\title{
Knowledge and Utilisation of Long Lasting Insecticidal Nets and Intermittent Preventive Treatment of Malaria in Pregnancy among Pregnant Women and Children Under Five Years in Selected Communities of Ogun State, Nigeria
}

\author{
Adeneye $\mathrm{AK}^{1^{*}}$, Jegede $\mathrm{AS}^{2}$, Mafe $\mathrm{MA}^{1}$ and Nwokocha $\mathrm{EE}^{2}$ \\ ${ }^{1}$ Public Health and Epidemiology Department, Nigerian Institute of Medical Research, Nigeria \\ ${ }^{2}$ Department of Sociology, Faculty of the Social Sciences, University of Ibadan, Ibadan, Nigeria
}

*Corresponding author: Adeneye AK, Public Health and Epidemiology Department, Nigerian Institute of Medical Research, 6 Edmund Crescent, P.M.B 2013, Yaba, Lagos, Nigeria, Tel: +234-805-788-7698

\begin{abstract}
Background: There are very few evidence from studies on the knowledge, accessibility and use of LLIN and IPTp in communities of Ogun State following the promotion of the malaria control strategies across the country. This study was therefore conducted to examine the knowledge, accessibility and use of malaria control strategies that include long-lasting insecticidal nets (LLINs), and intermittent preventive treatment of malaria in pregnancy (IPTp) within the context of rolling back malaria in Ogun State, Nigeria.
\end{abstract}

Methods: It was a descriptive cross-sectional study conducted in communities of ljebu North and Yewa North local government areas (LGAs) of Ogun State. Data collection involved use of semi-structured questionnaire and focus group discussions among pregnant women attending antenatal clinics and mothers of under-five children. Secondary data were also collected through hospital records. Quantitative and qualitative data were analysed using Epi Info 6.04a and Textbase Beta softwares respectively.

Results: Hospital stock records showed inadequate and inconsistent supplies of ACTs to hospitals surveyed. While 45.5\% (61.1\% Yewa North vs. 29.2\% ljebu North) knew LLIN, only $23.6 \%$ (27.9\% mothers of under-five vs. $19.8 \%$ pregnant women) used it. Lack of awareness was the major reason for non-use of LLINs (71.3\%). Nearly half $(47.3 \%)$ of the pregnant women knew about IPTp, while $43.5 \%$ (30.5\% private vs. $52.2 \%$ public) had received at least one dose of IPTp. Their awareness and use of LLIN and IPTp were significantly determined by locality, age, education and health facility visited for antenatal care $(p<0.05)$.
Conclusions: Low awareness and use of LLIN and IPTp in study communities was highly demonstrated. Adequate information and the malaria control commodities need to be made available and accessible in the study communities and Ogun State in general.

\section{Keywords}

Knowledge, Use, Long lasting insecticidal nets, Intermittent preventive treatment of malaria in pregnancy, Pregnant women, Children under five years, Nigeria

\section{Introduction}

Malaria remains a major public health challenge globally, particularly in Nigeria [1]. Pregnant women and their unborn babies as well as children under five years of age are among the groups most vulnerable to malaria. With 25-30 million women becoming pregnant in malaria endemic areas of Africa [2,3] and approximately 100 million episodes of malaria occurring each year among children under five years worldwide, more than one million deaths are attributable to the disease within same period of one year. Furthermore, with $60 \%$ of outpatient visits, 30\% hospitalizations and $20-25 \%$ infant and child mortality attributable to malaria, an estimated 300,000 children die of malaria each year [4-6]. In addition, it increases risk of adverse pregnancy outcomes such as anaemia, miscarriage, stillbirth, premature de-

Citation: Adeneye AK, Jegede AS, Mafe MA, Nwokocha EE (2020) Knowledge and Utilisation of Long Lasting Insecticidal Nets and Intermittent Preventive Treatment of Malaria in Pregnancy among Pregnant Women and Children Under Five Years in Selected Communities of Ogun State, Nigeria. Int J Trop Dis 3:040. doi.org/10.23937/2643-461X/1710040

Accepted: November 28, 2020; Published: November 30, 2020

Copyright: (C) 2020 Adeneye AK, et al. This is an open-access article distributed under the terms of the Creative Commons Attribution License, which permits unrestricted use, distribution, and reproduction in any medium, provided the original author and source are credited. 
livery and low birth weight babies in expectant mothers and convulsions, jaundice, increased risk of neonatal death, acute renal failure, neurological problems, epilepsy and impaired cognitive development [7-13].

In Nigeria where maternal mortality ratio is 512 per 100,000 live births, under five mortality rate is 132 per 1,000 live births [14] and malaria is holo-endemic, the disease causes up to $11 \%$ of maternal mortality and is consistently recorded as one of the five leading causes of mortality among children under five years. In addition to the direct health impact of malaria, its severe socio-economic burdens on the country at large is estimated at an annual loss of about 132 billion naira in form of treatment cost, prevention, and loss of work time to mention a few [6].

Currently, one of the prioritised and advocated cost-effective malaria control strategies is the use of long lasting insecticidal nets (LLINs) with special focus on children under five years and pregnant women [15]. In addition to LLIN use, protection from malaria in pregnancy include use of administration of regular treatment doses of the antimalarial sulphadoxine-pyrimethamine as intermittent preventive treatment of malaria in pregnancy (IPTp) during routine antenatal clinic visits. Two or more doses of IPTp after the end of the first trimester are recommended by the World Health Organisation [16-18].

Studies have shown that adequate malaria control could prevent $3-8 \%$ of infant deaths $[2,19]$. The use of LLINs have been shown to reduce the number of malaria episodes by as much as $50 \%$ and childhood mortality by $20 \%$ [15] and IPTp using sulphadoxine-pyrimethamine reduce malaria-related complications in pregnancy $[20,21]$.

A major effort to roll back malaria (RBM) in line with the National Malaria Strategic Plan in Nigeriahas been on-going with the aim of scaling-up malaria prevention and treatment interventions to universal scale. Sequel to the 2000 Abuja Summit on RBM, the Nigerian Government has been pro-active in promoting and providing LLINs and IPTp $[1,22]$. The intervention policies and strategies of free distribution of LLINs and IPTp based on WHO recommendation were adopted in the country in 2001 and 2004 respectively [23]. For effective implementation of the IPTp policy, the National Guidelines and Strategies for malaria prevention and control during pregnancy document was printed and distributed to all the States, for onward distribution to the local government areas (LGAs) and health facilities [24,25].

The RBM 'Strategic Framework for Coordinated National Action in Scaling-up Insecticide-Treated Netting Programmes in Africa' promoted a coordinated national action and advocates sustained public provision of targeted subsidies to maximize public health benefits of the treated nets, alongside support and stimulation of the private sector [26].
The effective control of malaria in pregnant women and children under five years of age is usually a function of several factors such as those relating to knowledge, attitude and practices [27-31]. In Ogun State, the systematic study of these factors relating to malaria in pregnancy and children under five years has not been adequately conducted. This paper therefore sought to explore issues relating to the prevention of malaria among pregnant women and children under five years, adherence to the national malaria control policy on the prevention of malaria and also examine the factors that influence the use of LLIN and IPTp among the target populations in Ogun State, Nigeria.

\section{Methods}

\section{Study area}

The study was carried out in two randomly selected semi-urban local government areas (LGAs) of Ogun State, located in South-Western part of Nigeria where malaria is holo-endemic and malaria control programme is being implemented. The LGAs are namely: ljebu North and Yewa North. The LGAs are two of twenty LGAs in Ogun State. The ljebu North and Yewa North LGAs are located $140 \mathrm{~km}$ North-East and $170 \mathrm{~km}$ North of Lagos in the rain forest zone of South-West Nigeria. Two communities (Oru/Awa-Ilaporu and Mamu) in Ijebu North LGA and two communities (Igbogila and Ijoun) in Yewa North were randomly selected for the study. Here, the LGAs were used as the study units. The inhabitants of the two LGAs are predominantly farmers and traders and there is high transmission of malaria during the rainy season between April and November [32-34]. The location of the two study LGAs in Ogun State is displayed in Figure 1.

Basic social amenities like roads, water, health facilities and educational institutions abound in the selected LGAs. The health programmes in the LGAs are planned and managed by the Primary Health Care Department at the LGA headquarters. The health facilities in Ijebu North LGA include a General Hospital, Primary Healthcare Centres (PHCs), health clinics, health posts and private clinics. Yewa North LGA also has a General Hospital, PHCs, health centres, health posts, private clinics and an alternative health clinic $[33,35,36]$.

\section{Study design}

This is a cross-sectional study on the awareness, availability and use of LLIN and IPTp in the context of the past RBM programme in ljebu North and Yewa North LGAs of Ogun State. The major target populations for the study were pregnant women and mothers of children under five years of age. A total of 233 mothers of children under five years and 262 pregnant women attending antenatal clinics were interviewed during the household and clinic survey respectively in the selected communities. 


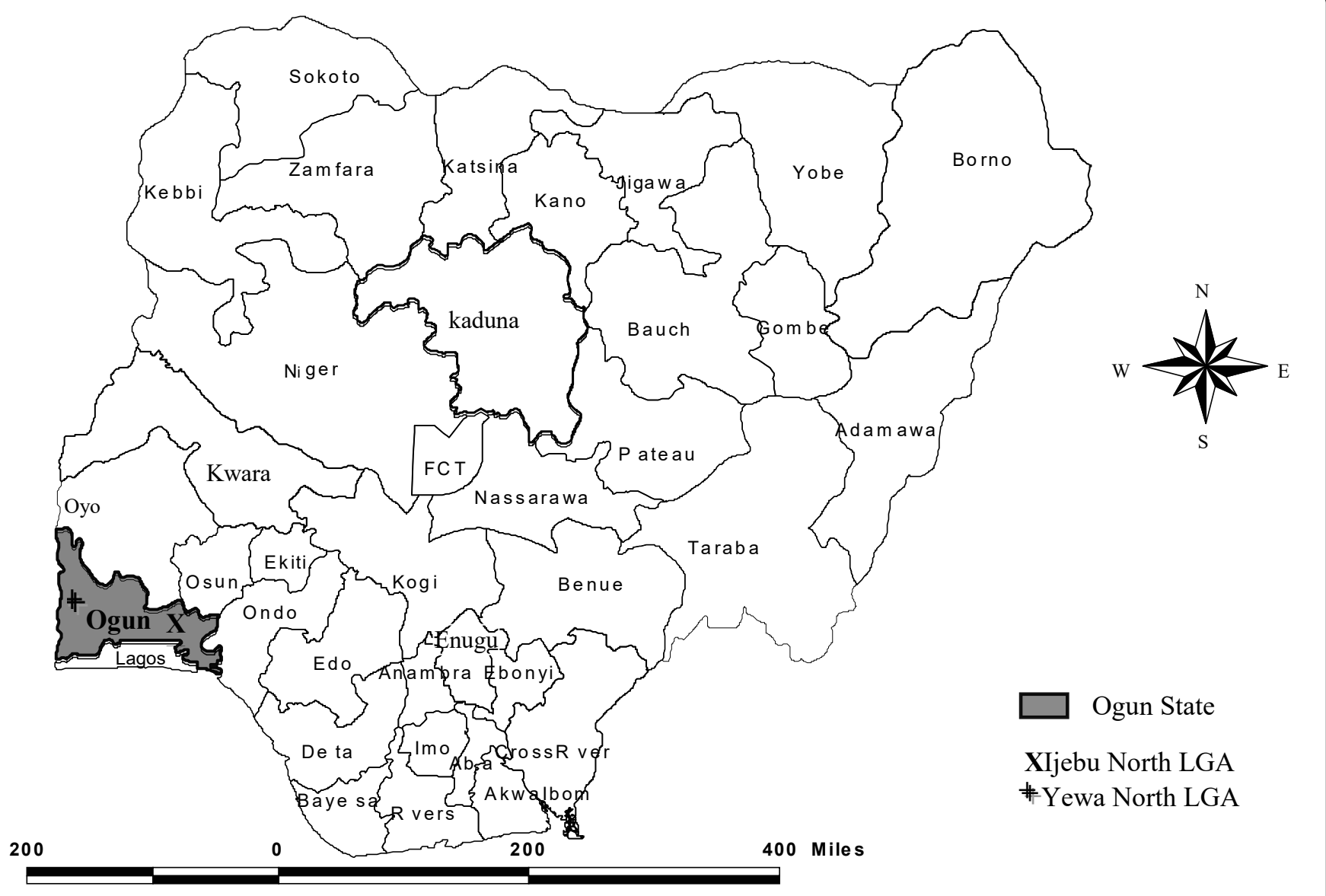

Figure 1: Map of Nigeria showing Ogun State, in which the study LGAs are spotted.

The mothers of children under five years old were selected using multi-stage sampling process with a combination of simple random and systematic sampling [37]. For the clinic survey, the sampling frame for the selection of the study units in the clinic survey was the list of pregnant women registered for antenatal care at the selected health facilities. They were randomly selected and interviewed on exit from the clinic. Here, the names of those interviewed on exit from the clinics were noted on each visit to the selected health facilities in order to avoid duplication of respondents. The lists of names noted were subsequently destroyed for purposes of confidentiality.

\section{Data collection procedures}

The study involved the use of interviewer-administered semi-structured questionnaires in clinic and household surveys, Focus Group Discussions (FGDs) and in-depth interviews. During the clinic survey, the observation method was also used to take note of available IEC materials such as posters on malaria prevention and treatment that were displayed within the premises of health facilities visited. Similarly, the observation technique was adopted in noting IPTP provision and LLIN distribution at the facilities. In addition, secondary data were collected through hospital records. In this regard, records relating to LLIN supplies and distribution were checked at the health facilities surveyed. The data collection process first involved a formative qualitative study of people's perceptions, beliefs and practices concerning malaria prevention and treatment through FGDs and in-depth interviews. This was then followed with the use of questionnaires in household and clinic surveys. Prior to the actual survey, a pretesting was done to ascertain the validity and reliability of the questionnaire and data collection procedures. This was done to test the adequacy and consistency of the research design and questionnaire.

The main sections of the questionnaire from which the focus of this paper was derived included those that probed the background characteristics of the respondent such as age, religion, level of education, marital status and occupation. Sections of the questionnaire also comprised questions probing awareness and use of IPTp, knowledge of benefits of IPTp, number of IPTp doses received among the pregnant women and availability and access to IPTp for the pregnant women. Questions on awareness of LLIN and its use in malaria prevention in the home by the two categories of the study population, and their ability and willingness to pay for LLINs were also asked. These questions were included in the questionnaire following outcome of the formative study.

\section{Ethical considerations}

Approvals at the State, Local, and Community levels were obtained prior to the commencement of the study in the communities. Ethical approval was obtained for 
the research protocol for the larger study from the University of Ibadan/University College Hospital (UI/UCH) Ethics Committee (UI/EC/11/0075) and was carried out in accordance with universal ethical principles. The informed consent of all the research participants for the study was sought and obtained in written form using an informed consent form to signify their willingness to participate in the research.

\section{Data analysis}

The quantitative and qualitative data for each phase of the study were analyzed using Epi Info 6.04a and the textual analysis programme Textbase Beta softwares respectively. Statistical analyses of the quantitative data were conducted using analysis of variance and chi-square tests at $95 \%$ level of significance. Analysis of variance (ANOVA) was used in showing the relationship between measurements of the mean and the variance or "random error" of each sub-group under study in order to provide information needed to determine if the difference between the two is significant, while chi-square which is a non-parametric test of statistical significance for bivariate tabular analysis, was used to know whether or not two different samples (of people) are different enough in some characteristics or aspects of respondents' behaviour.

\section{Results}

\section{Socio-demographic characteristics of respondents}

Of the four hundred and ninety-five respondents surveyed, two hundred and sixty-two (52.9\%) were pregnant women and two hundred and thirty-three (47.1\%) were mothers of children under five years old. Overall, $50.9 \%$ and $49.1 \%$ of the respondents were from Yewa North and ljebu North local government area respectively. A larger number (68.5\%) of respondents were Christians and $97.6 \%$ were married. Most respondents were artisans (38.4\%) and traders $(25.9 \%)$ and had some formal education. Of the two hundred and sixty-two pregnant women interviewed, $40.1 \%$ were from private hospitals and $59.9 \%$ were from public hospitals. The ages of the respondents ranged from 16 to 40 years, with a mean age of 28.8 years ( 27.9 years among pregnant women vs. 28.7 years among mothers of children under five years) and a median of 30 years ( 30 years among pregnant women vs. 23 years among mothers of children under five years). The socio-demographic characteristics of the respondents are presented in Table 1.

\section{Respondents' awareness, perception and use of Long Lasting Insecticide Nets (LLINs)}

Exposure to information about LLINs was low; few (45.5\%) of the four hundred and ninety-five respondents $(46.4 \%$ of mothers of children under five years vs. $44.7 \%$ of pregnant women) interviewed had seen or heard something about LLINs as shown in Table 2. Statistical test using ANOVA showed that those that had heard of LLINs had a mean age of 26.4 years compared with 25.1 years for those not aware of the material ( $p$ $<0.05)$.

In contrast to large number of respondents who were aware of LLINs, only $23.6 \%$ were using the treated material for malaria prevention $(27.9 \%$ of mothers of children under five years vs. $19.8 \%$ of pregnant women) as displayed in Table 2.

The educational status of the respondents was directly related to their probability of having seen or heard information on $\left(\chi^{2}=38.48\right.$, df $\left.=6, p<0.05\right)$ and use $\left(\chi^{2}=55.89, d f=6, p<0.05\right)$ of LLINs as displayed in Figure 2. Similarly, the LGA [61.1 Yewa North vs. 29.2 ljebu North] $\left(\chi^{2}=51.81, \mathrm{df}=2, \mathrm{p}<0.05\right)$ and community of residence $\left(\chi^{2}=61.28, d f=6, p<0.05\right)$ of the respondents influenced their probability of having seen or heard information on LLINs. Statistical test further revealed that the community of residence of the respondents influenced their probability of having used LLINs $\left(x^{2}=60.07, d f=6, p<0.05\right)$. On the contrary, the age of the respondents had no significant effect on their use of LLINs $(p>0.05)$.

Figure 3 shows that pregnant women registered for antenatal care at public hospitals (56.7\%) had higher level of awareness of LLINs than those at private hospitals $(26.7 \%)\left[\chi^{2}=24.13, d f=2, p<0.05\right]$. Similarly, more (26.8\%) pregnant women registered at public hospitals for antenatal care use LLINs compared to $9.5 \%$ among those registered at private hospitals. The odds ratio of 0.29 has a $95 \%$ confidence interval of $0.13-0.64$, and chi square with Yates correction is 10.68 with a $p$-value < 0.05 .

The LLIN use duration among the respondents ranged from 1 and 72 months with a mean of 5 months (7 months Yewa North vs. 3.4 months ljebu North).

Among the 117 respondents that use LLINs, majority (97.4\%) of them had positive perception about the use of LLINs. On the contrary, $2.6 \%$ were indifferent in their response. Of those with positive perception, $50.9 \%$ considered it to be effective in preventing mosquito bite and $49.1 \%$ said the net is more cost-effective than other means of preventing mosquito bites.

\section{Reasons for non-use of LLINs among respondents}

The most common reason given by the respondents for not using LLIN was lack of awareness (71.0\%). Other reasons given included: Preference for chemical spraying (9.0\%); "can't afford to buy" (7.0\%); "net causes heat" (4.0\%); "not interested in nets" (4.0\%); and "don't know where to buy it" (2.0\%). A few (3.0\%) others did not give any reasons.

Among FGD participants, there were mixed reactions reflecting the different reasons given to justify their non-use of LLINs. A female participant in a focus group in Oru/Awa/llaporu pointed out that: 
Table 1: Socio-demographic characteristics of respondents.

\begin{tabular}{|c|c|c|c|c|c|c|}
\hline \multirow{2}{*}{$\begin{array}{l}\text { Socio-demographic } \\
\text { characteristics } \\
\text { Local Government Area }\end{array}$} & \multicolumn{2}{|c|}{ Pregnant women } & \multicolumn{2}{|c|}{ Mothers of under- 5 children } & \multicolumn{2}{|c|}{ Total } \\
\hline & & & & & & \\
\hline \multirow{3}{*}{$\begin{array}{l}\text { Yewa North } \\
\text { ljebu North }\end{array}$} & Number & $\%$ & Number & $\%$ & Number & $\%$ \\
\hline & 133 & $(50.8)$ & 119 & $(51.1)$ & 252 & $(50.9)$ \\
\hline & 129 & $(49.2)$ & 114 & $(48.9)$ & 243 & $(49.1)$ \\
\hline Total & 262 & $(52.9)$ & 233 & $(47.1)$ & 495 & $(100.0)$ \\
\hline \multicolumn{7}{|l|}{ Communities } \\
\hline Igbogila & 123 & $(46.9)$ & 109 & $(46.8)$ & 232 & $(46.9)$ \\
\hline ljoun & 10 & $(3.8)$ & 9 & $(3.9)$ & 19 & (3.8) \\
\hline Oru/Awa/llaporu & 108 & $(41.2)$ & 96 & $(41.2)$ & 204 & $(41.2)$ \\
\hline Mamu & 21 & $(8.0)$ & 19 & $(8.2)$ & 40 & (8.1) \\
\hline Total & 262 & $(52.9)$ & 233 & $(47.1)$ & 495 & $(100.0)$ \\
\hline \multicolumn{7}{|l|}{ Religion } \\
\hline Christianity & 193 & $(73.7)$ & 146 & $(62.7)$ & 339 & $(68.5)$ \\
\hline Islam & 69 & $(26.3)$ & 83 & $(35.6)$ & 152 & $(30.7)$ \\
\hline Traditional & 0 & $(0.0)$ & 4 & $(1.7)$ & 4 & $(0.8)$ \\
\hline Total & 262 & $(52.9)$ & 233 & $(47.1)$ & 495 & $(100.0)$ \\
\hline \multicolumn{7}{|l|}{ Marital Status } \\
\hline Never married & 3 & $(1.1)$ & 6 & $(2.6)$ & 9 & (1.8) \\
\hline Married & 258 & $(98.5)$ & 225 & $(96.6)$ & 483 & $(97.6)$ \\
\hline Divorced & 1 & $(0.4)$ & 1 & $(0.4)$ & 2 & $(0.4)$ \\
\hline Separated & 0 & $(0.0)$ & 1 & $(0.4)$ & 1 & $(0.2)$ \\
\hline Total & 262 & $(52.9)$ & 233 & $(47.1)$ & 495 & $(100.0)$ \\
\hline \multicolumn{7}{|l|}{ Education } \\
\hline None & 52 & $(19.8)$ & 42 & $(18.0)$ & 94 & $(19.0)$ \\
\hline Primary & 86 & $(32.8)$ & 52 & $(22.4)$ & 138 & $(27.9)$ \\
\hline Secondary & 103 & $(39.3)$ & 111 & $(47.6)$ & 214 & $(43.2)$ \\
\hline Post-secondary & 21 & $(8.0)$ & 28 & $(12.0)$ & 49 & (9.9) \\
\hline Total & 262 & $(52.9)$ & 233 & $(47.1)$ & 495 & $(100.0)$ \\
\hline \multicolumn{7}{|l|}{ Occupation } \\
\hline Unemployed & 1 & $(0.4)$ & 1 & $(0.4)$ & 2 & $(0.4)$ \\
\hline Housewife & 23 & $(8.8)$ & 20 & $(8.6)$ & 43 & (8.7) \\
\hline Farming & 41 & $(15.6)$ & 17 & $(7.3)$ & 58 & $(11.7)$ \\
\hline Artisan & 76 & $(29.0)$ & 114 & $(48.9)$ & 190 & $(38.4)$ \\
\hline Civil servant & 19 & $(7.3)$ & 25 & $(10.9)$ & 44 & $(8.9)$ \\
\hline Professional (e.g. Banker) & 8 & $(3.1)$ & 12 & $(5.2)$ & 20 & $(4.0)$ \\
\hline Trading & 86 & $(32.8)$ & 42 & $(18.0)$ & 120 & $(25.9)$ \\
\hline Student & 5 & $(1.9)$ & 0 & $(0.0)$ & 5 & $(1.0)$ \\
\hline Other & 3 & $(1.1)$ & 0 & $(0.0)$ & 3 & $(0.6)$ \\
\hline No response & 0 & $(0.0)$ & 2 & $(0.9)$ & 2 & $(0.4)$ \\
\hline Total & 262 & $(52.9)$ & 233 & $(47.1)$ & 495 & $(100.0)$ \\
\hline
\end{tabular}

Table 2: Awareness and use of LLIN among respondents.

\begin{tabular}{|l|l|l|l|l|l|l|}
\hline & \multicolumn{2}{l}{$\begin{array}{l}\text { Mothers of children under five } \\
\text { years }\end{array}$} & Pregnant women & \multicolumn{2}{l|}{ Total } \\
\cline { 2 - 7 } & Aware & Use & Aware & Use & Aware & Use \\
\hline Yes & $108(46.4)$ & $65(27.9)$ & $117(44.7)$ & $52(19.8)$ & $225(45.5)$ & $117(23.6)$ \\
\hline No & $124(53.2)$ & $166(71.2)$ & $114(55.0)$ & $210(80.2)$ & $268(54.1)$ & $376(76.0)$ \\
\hline Undecided & $1(0.4)$ & $2(0.9)$ & $1(0.4)$ & $0(0)$ & $2(0.4)$ & $2(0.4)$ \\
\hline Total & $233(100.0)$ & $233(100.0)$ & $262(100.0)$ & $262(100.0)$ & $495(100.0)$ & $495(100.0)$ \\
\hline
\end{tabular}




\section{Aware use}

83.7

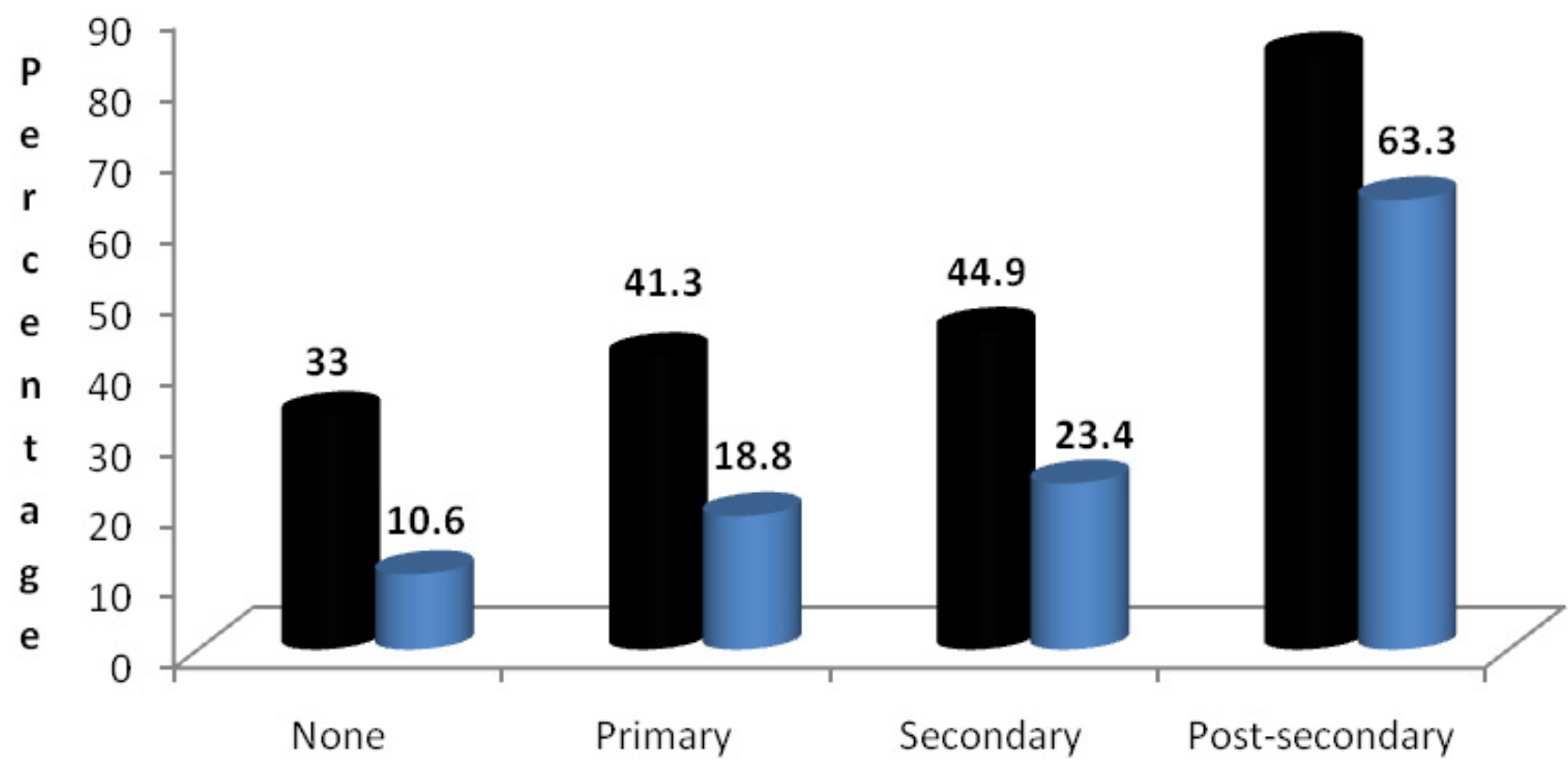

Level of education

Figure 2: Respondents awareness and use of LLIN according to level of education.

\section{- LLIN Awareness $\quad$ LLIN Use}

56.7

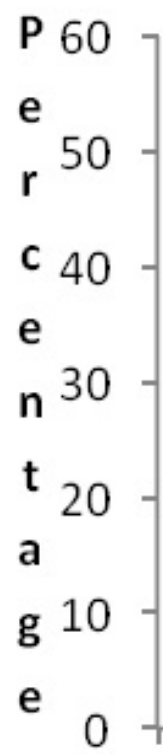

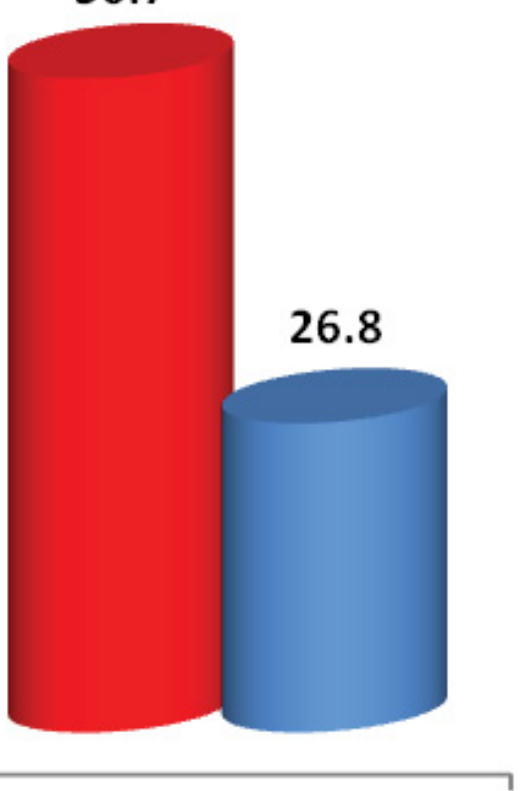

Private Hospital

Public Hospital

\section{Health facility type}

Figure 3: Awareness and use of LLIN among pregnant women according to health facility type attended for antenatal care. 
Table 3: Awareness of IPTp among pregnant women and their background characteristics.

\begin{tabular}{|c|c|c|c|c|c|c|}
\hline \multirow[b]{3}{*}{ Facility type } & \multicolumn{6}{|c|}{ Awareness of IPTp } \\
\hline & \multicolumn{2}{|l|}{ Yes } & \multicolumn{2}{|l|}{ No } & \multicolumn{2}{|l|}{ Total } \\
\hline & Number & $\%$ & Number & $\%$ & Number & $\%$ \\
\hline Private & 34 & 32.4 & 71 & 67.6 & 105 & 40.1 \\
\hline Public & 90 & 57.3 & 67 & 42.7 & 157 & 59.9 \\
\hline Total & 124 & 47.3 & 138 & 52.7 & 262 & 100.0 \\
\hline$x^{2}=15.78 \quad d f=1$ & \multicolumn{6}{|l|}{$p<0.05$} \\
\hline \multicolumn{7}{|l|}{ Local Governemnt Area } \\
\hline Yewa North & 105 & 78.9 & 28 & 21.1 & 133 & 50.8 \\
\hline ljebu North & 19 & 14.7 & 110 & 85.3 & 129 & 49.2 \\
\hline Total & 124 & 47.3 & 138 & 52.7 & 262 & 100.0 \\
\hline$x^{2}=105.77 \quad d f=1$ & \multicolumn{6}{|c|}{$p<0.05$} \\
\hline \multicolumn{7}{|l|}{ Communities } \\
\hline Igbogila & 95 & 77.4 & 28 & 22.8 & 123 & 46.9 \\
\hline ljoun & 10 & 100.0 & 0 & 0.0 & 10 & 3.8 \\
\hline Oru/Awa/llaporu & 19 & 19.0 & 89 & 82.4 & 108 & 41.2 \\
\hline Mamu & 0 & 0.0 & 21 & 100.0 & 21 & 8.1 \\
\hline Total & 124 & 47.3 & 138 & 52.7 & 262 & 100.0 \\
\hline$X^{2}=112.44 \quad$ df $=3$ & \multicolumn{6}{|l|}{$p<0.05$} \\
\hline \multicolumn{7}{|l|}{ Education } \\
\hline None & 28 & 53.8 & 24 & 46.2 & 52 & 19.8 \\
\hline Primary & 44 & 51.2 & 42 & 48.8 & 86 & 32.8 \\
\hline Secondary & 37 & 35.9 & 66 & 64.1 & 103 & 39.3 \\
\hline Post-secondary & 15 & 71.4 & 6 & 28.6 & 21 & 8.0 \\
\hline Total & 124 & 47.3 & 138 & 52.7 & 262 & 100.0 \\
\hline
\end{tabular}

Table 4: IPTp use among respondents by their background characteristics.

\begin{tabular}{|c|c|c|c|c|}
\hline \multirow{3}{*}{ Health facility type } & \multicolumn{4}{|l|}{ Use of IPTp } \\
\hline & Yes & No & \multicolumn{2}{|l|}{ Total } \\
\hline & Number $\%$ & Number $\%$ & Number & $\%$ \\
\hline Private & 30.5 & 69.5 & 105 & 40.1 \\
\hline Public & 52.2 & 47.8 & 157 & 59.9 \\
\hline Total & 43.5 & 56.5 & 262 & 100.0 \\
\hline$X^{2}=12.11 \quad d f=1$ & 0.05 & & & \\
\hline \multicolumn{5}{|c|}{ Local Governemnt Area } \\
\hline Yewa North & 73.7 & 26.3 & 133 & 50.8 \\
\hline ljebu North & 12.4 & 87.6 & 129 & 49.2 \\
\hline Total & 43.5 & 56.5 & 262 & 100.0 \\
\hline$X^{2}=0.85 \quad d f=1$ & & & & \\
\hline \multicolumn{5}{|l|}{ Communities } \\
\hline Igbogila & 71.5 & 28.5 & 123 & 46.9 \\
\hline ljoun & 100.0 & 0.0 & 10 & 3.8 \\
\hline Oru/Awa/llaporu & 14.8 & 85.2 & 108 & 41.2 \\
\hline Mamu & 0.0 & 100.0 & 21 & 8.1 \\
\hline Total & 43.5 & 56.5 & 262 & 100.0 \\
\hline$x^{2}=104.67 \quad d f=3$ & 0.05 & & & \\
\hline \multicolumn{5}{|l|}{ Education } \\
\hline None & 50.0 & 50.0 & 52 & 19.8 \\
\hline
\end{tabular}




\begin{tabular}{|l|r|r|r|r|r|r|}
\hline Primary & 40 & $\mathbf{4 6 . 5}$ & 46 & 53.5 & 86 & 32.8 \\
\hline Secondary & 33 & $\mathbf{3 2 . 0}$ & 70 & 68.0 & 103 & 39.3 \\
\hline Post-secondary & 15 & $\mathbf{7 1 . 4}$ & 6 & 28.6 & 21 & 8.0 \\
\hline Total & 114 & $\mathbf{4 3 . 5}$ & 148 & 56.5 & 262 & 100.0 \\
\hline $\mathrm{X}^{2}=13.38 \quad \mathrm{df}=3 \quad \mathrm{p}<0.05$ & & & & & \\
\hline
\end{tabular}

...none of the eight of us seated here have the treated net. It is not even available in our market.

Another female participant stated that:

...there was a time the net was available in abundance at the healthcentre and it was being given free, but this is not the case anymore because the health centre no longer have net to give.

In Igbogila, a female participant stated that:

... why I don't have and use a treated net is that there was no supply of the nets to the government health centre I attended for antenatal care at the time I was pregnant. I was not the only one affected, it was a whole set of women attending antenatal clinic then. We were asked to come for the net later ...soon after, I lost interest.

\section{Awareness of, access to and use of IPTp among pregnant women}

The pregnant women interviewed reported to have been attending antenatal clinics for the period that ranged between 1 to 9 months with an average of 3.2 months and a median of 3 months. Table 3 showed that only $47.3 \%$ of interviewed pregnant women who had reached the 20-24 weeks gestation age were aware of the IPTp (32.4\% private vs. $57.3 \%$ public, $73.7 \%$ Yewa North vs. $12.4 \%$ ljebu North) contrary to $43.5 \%$ that reported they had taken at least a dose of the preventive therapy (30.5\% private vs. $52.2 \%$ public) as displayed in Table 4.

Factors that include facility type being attended for antenatal care, community and LGA of residence and education had significant influence on the awareness of IPTp among the pregnant women as displayed in Table 3. Of these four factors, only the LGA of residence had no significant influence on the use of IPTp among the pregnant women in Table 4. Pregnant women in ljoun community had a longer period of awareness of IPTp with an average of 5 months compared to 4 months for those in Oru/Awa/llaporu and Mamu respectively and 2.5 months in Igbogila $\left(\chi^{2}=28.82, d f=3, p<0.05\right)$.

The access to IPTp shown in Table 4 was significantly influenced by the number of visits the pregnant women had made to the clinic for antenatal care $\left(\chi^{2}=28.71, \mathrm{df}\right.$ $=16, p<0.05)$. On the contrary, age and religion had no significant effect on their level of awareness and use of IPTp $(p>0.05)$. Multiple regressions showed three key factors that were associated with IPTp awareness and use: facility type being attended for antenatal care; LGA
Table 5: Number IPTp doses received by pregnant women.

\begin{tabular}{|l|l|l|}
\hline $\begin{array}{l}\text { Number of IPTp } \\
\text { doses received }\end{array}$ & Number & $\%$ \\
\hline 0 & 147 & 56.1 \\
1 & 81 & 30.9 \\
2 & 24 & 9.2 \\
3 & 8 & 3.1 \\
4 & 1 & 0.4 \\
\hline 5 & 1 & 0.4 \\
\hline Total & 262 & 100.0 \\
\hline
\end{tabular}

of residence; and occupation.

\section{Doses of IPTp drugs taken by the pregnant women}

The distribution of the pregnant women by the number of IPTp doses received is presented in Table 5. Only $13.0 \%$ had received at least two doses of IPTp. More than half $(56.1 \%)$ of the women had not received any dose of IPTp due to non-availability of the preventive dose at the health facilities.

Statistical test using ANOVA showed that more pregnant women in Yewa LGA (mean of 1 dose) had received more doses than those in ljebu North (mean of 0.2 dose) as illustrated in Figure $4\left(\chi^{2}=81.4, d f=1, p<0.05\right)$. Statistical test further showed that at the community level, the pregnant women had received an average of 1, 2, 0 and 0 doses of IPTp drugs in Igbogila, ljoun, Oru/Awa/ Ilaporu and Mamu respectively $\left(\chi^{2}=92.43, \mathrm{df}=3, p<\right.$ $0.05)$. The number of IPTp doses taken was affected by how long the pregnant women had been attending antenatal clinics $\left(\chi^{2}=71.55, \mathrm{df}=40, p<0.05\right)$. More antenatal clinic attendance with an average of 3.2 months was reported among pregnant women who had taken at least a dose of the IPTp drug. This is contrary to an average of 2 months reported by those who had not taken any dose $\left(x^{2}=7.93, d f=2, p<0.05\right)$. Those attending public hospitals (mean of 0.7 dose) had received more doses than those attending private hospitals (mean of 0.5 dose) $\left(\chi^{2}=8.73, d f=1, p<0.05\right)$.

On the complementary use of LLIN and IPTp for effective malaria prevention, results showed that only $13.4 \%$ of the pregnant women had taken at least a dose of IPTp drug and used a treated net for this purpose.

\section{Knowledge of benefits of IPTp among pregnant women}

Among the pregnant women interviewed, only 114 (43.5\%) knew and could describe the purpose and ben- 


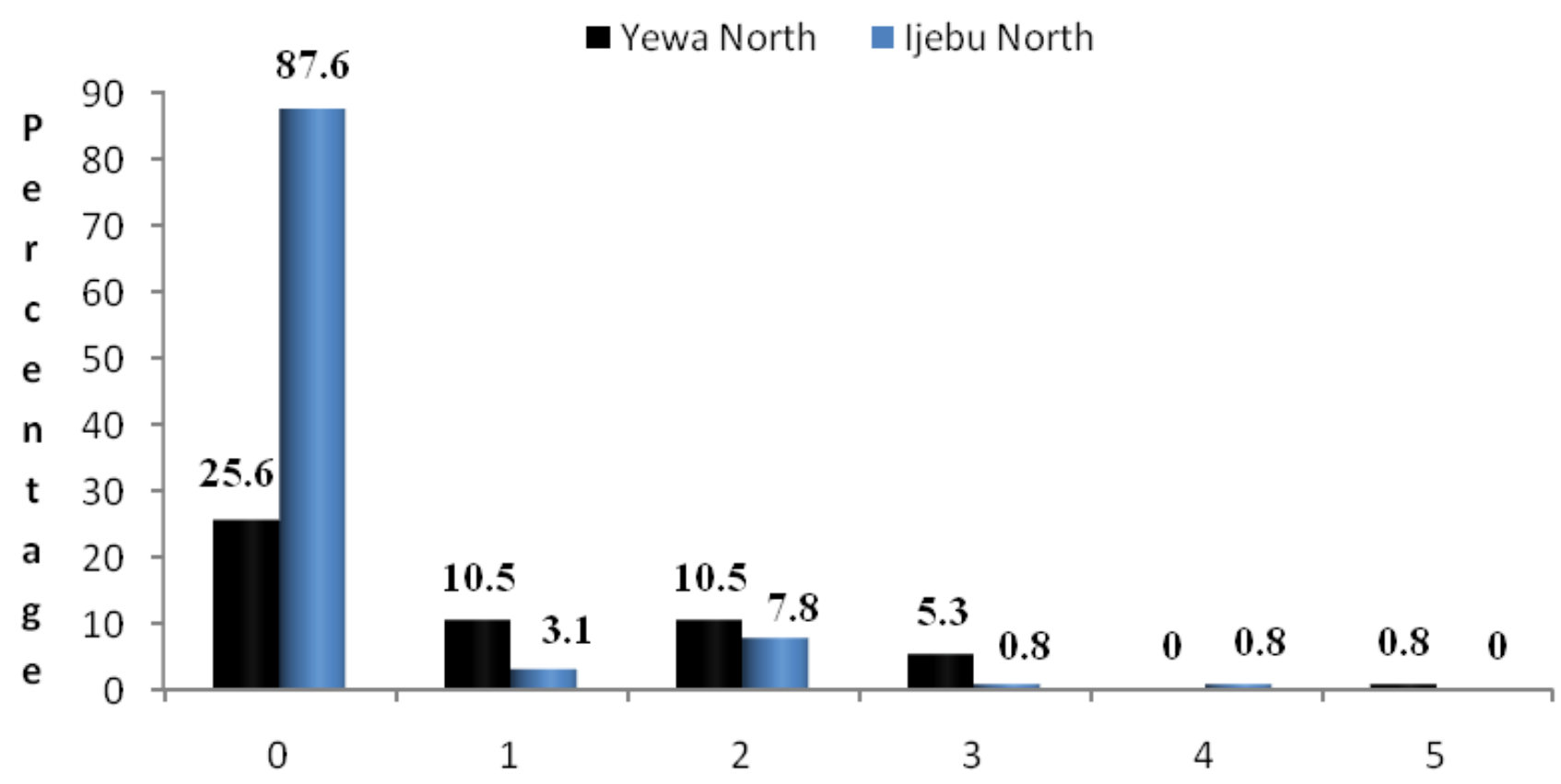

\section{Number of IPTp doses received}

Figure 4: Number of IPTp doses received by pregnant women by their LGA.

Table 6: Stocks of IPTp drugs and LLINs at surveyed health facilities 2006-2008.

\begin{tabular}{|c|c|c|c|c|c|c|c|}
\hline \multirow[b]{2}{*}{ Community/Facility } & \multirow[b]{2}{*}{ Facility type } & \multicolumn{3}{|c|}{$\begin{array}{l}\text { IPTp drugs } \\
\text { (Packs of Fansidar }{ }^{\circledast} / \text { Malwin }^{\circledR} \text { supplied) }\end{array}$} & \multicolumn{3}{|c|}{ LLIN } \\
\hline & & 2006 & 2007 & 2008 & 2006 & 2007 & 2008 \\
\hline \multicolumn{8}{|l|}{ ljebu North LGA } \\
\hline \multicolumn{8}{|l|}{ Oru/Awa-Ilaporu } \\
\hline PHC, Oru & Public & 0 & 47 & 52 & 0 & 0 & 0 \\
\hline Opeolu Clinic, Oru & Private & 0 & 0 & 0 & 0 & 0 & 0 \\
\hline \multicolumn{8}{|l|}{ Mamu } \\
\hline Health Post & Public & 0 & 0 & 0 & 0 & 0 & 0 \\
\hline Fagoc Clinic \& Maternity & Private & 0 & 0 & 0 & 0 & 0 & 0 \\
\hline \multicolumn{2}{|l|}{ Total } & 0 & 47 & 52 & 0 & 0 & 0 \\
\hline \multicolumn{8}{|l|}{ Yewa North LGA } \\
\hline \multicolumn{8}{|l|}{ Igbogila } \\
\hline Primary Health Centre & Public & 1,000 & 100 & 100 & $0 \varepsilon$ & 80 & 80 \\
\hline Novia Hospital & Private & 0 & 0 & 0 & 0 & 0 & 0 \\
\hline Ekisola Medical Clinic & Private & 0 & 0 & 0 & 0 & 0 & 0 \\
\hline \multicolumn{8}{|l|}{ ljoun } \\
\hline Primary Health Centre & Public & 0 & 0 & 0 & 200 & 250 & 220 \\
\hline \multicolumn{2}{|l|}{ Total } & 1,000 & 100 & 100 & 200 & 330 & 300 \\
\hline \multicolumn{2}{|l|}{ Grand Total } & 1,000 & 147 & 152 & 200 & 350 & 300 \\
\hline
\end{tabular}

efits of IPTp (74.4\% Yewa North vs. $11.6 \%$ ljebu North; $31.4 \%$ private vs. $51.6 \%$ public) while more than half (55.5\%) did not know its benefits. Results showed that $73.2 \%$ and $100.0 \%$ of pregnant women in Igbogila and ljoun knew the purpose and benefits of IPTp while very few (13.9\%) and none of those in Oru/Awa/llaporu and Mamu did respectively.
Of the 114 that knew and could describe the purpose and benefits of IPTp, $84.2 \%$ described it as a presumptive treatment of malaria in pregnancy and $15.8 \%$ stated that it is taken to prevent malaria-related complications in pregnancy for the mother and the unborn child. Probability of knowing the benefits of IPTp was positively associated with education, ranging from $50.0 \%$ (no formal 
education) to $71.4 \%$ (post-secondary) $\left(\chi^{2}=18.15, \mathrm{df}=\right.$ $6, p<0.05)$.

\section{Health facility records on IPTp drugs and LLIN sup- plies and availability of IEC materials}

Information relating to IPTp drugs and LLINs in stock over a three-year period (2006-2008) at the health facilities surveyed following examination of records are displayed in Table 6. The records of IPTp drugs in Table 6 showed that the supplies were grossly inadequate considering the population of children under five years and pregnant women in the LGAs and the number of women registered for antenatal care who require the IPTp drugs in health facilities surveyed presented in Table 7.

Indepth interviews with health workers at the health facilities visited showed that none of the facilities had the National Guidelines and Strategies for malaria prevention and control during pregnancy document which outline basic information to guide the health care providers on steps to take and drugs to use for effective prevention of malaria in pregnancy and management and follow-up of malaria cases.

The outcome of the observations made during the clinic survey taking note of available IEC materials such as posters and leaflets with messages on malaria prevention and treatment showed that none of the health facilities visited displayed any IEC materials within their premises and neither did any of the health workers at the health facilities visited used any IEC materials in providing health education to their patients. Similarly, none of the communities studied had any billboard or IEC materials displaying messages relating to any of the malaria control interventions anywhere around.

All the health facilities visited except Igbogila PHC and Mamu Health Post had no LLINs in stock to give the targeted populations. However, IPTp drugs were seen being given the pregnant women under supervised administration by the health workers during antenatal visits only in the public health facilities except at ljoun PHC and Mamu Health Post.

\section{Discussion}

It is encouraging that a large number of respondents particularly those not using LLINs mentioned very few disadvantages of the treated nets as reasons for their non-use of the treated materials, and many advantages that were mainly malaria prevention and avoiding mosquito bites. The perceived disadvantages of the treated nets mentioned as reasons for the non-use of the treated materials are similar to those reported in a study among care-givers of children in Enugu, South East Nigeria [38]. The potency of killing mosquitoes cited as an advantage of LLINs by many respondents attests to their knowledge of mosquito bite as the route of malaria transmission. These results provide an optimistic foundation for launching and planning promotional programmes that will de-emphasise the perceived problems attributed to LLIN use by some respondents and emphasise on the benefits of LLIN use in the study communities and the State in general.

It is important to highlight the fact that the percentage of pregnant women using LLIN reported in this study is below the finding of a study on use of insecticide treated nets among pregnant women in Kilifi District, Kenya [39]. The percentage of LLIN use by pregnant women reported in the study is similar to that of Benin (20.0\%), higher than that of Malawi (15.0\%) but lower than those reported in Rwanda (60.0\%), Eritrea (50.0\%) and Kenya (37.0\%) [40].

The low use of LLINs as evident in the study and the gross inadequacy of stocks of the treated nets at health facilities visited presented in Table 6 may not be unconnected with the number of LLINs distributed between 2003 and 2008 across the country under the auspices of the national Malaria Control Programme [41]. The 6.5 million LLINs distributed in 2008 for example were nowhere near the 69.1-71.6 million LLINs needed to make scaling up for impact and ensure that the past RBM 2010 targets of $80 \%$ of pregnant women and children less than five years sleep under LLIN become a reality in the country [42]. A situation where some respondents

Table 7: Population of children under five years, pregnant women and number of women registered for antenatal care in surveyed health facilities in the study LGAs between 2006 and 2008.

\begin{tabular}{|c|c|c|c|}
\hline LGA/Community & $\begin{array}{l}\text { Expected number of } \\
\text { children }<5 \text { years }\end{array}$ & $\begin{array}{l}\text { Expected number of } \\
\text { pregnant women }\end{array}$ & $\begin{array}{l}\text { Registered number of pregnant } \\
\text { women in health facilities } \\
\text { visited }\end{array}$ \\
\hline \multicolumn{4}{|l|}{ ljebu North } \\
\hline Oru/Awa-Ilaporu & 2,982 & 3,492 & 654 \\
\hline Mamu & 583 & 683 & 322 \\
\hline Total & 3,565 & 4,175 & 976 \\
\hline \multicolumn{4}{|l|}{ Yewa North } \\
\hline Igbogila & 3,384 & 3,963 & 834 \\
\hline Ijoun & 272 & 318 & 480 \\
\hline Total & 3,656 & 4,281 & 1,314 \\
\hline Grand Total & 7,221 & 8,456 & 2,290 \\
\hline
\end{tabular}


reported not knowing where to buy LLINs attested to the unavailability of the treated materials in the study communities.

The level of awareness of LLINs reported in the study is very low compared to results reported in a study among children in Enugu, South East Nigeria [38]. The overall percentage of LLIN use reported in the study is similar to that reported in studies conducted in South East Nigeria [38] and Nepal [43] but higher than the findings of studies on home management of malaria in rural communities of Abeokuta, Nigeria in which none of the respondents interviewed used LLIN [44,45]. The percentage of LLIN use by children under five years reported in the study is above the finding in Ghana [46] but below the finding reported on the evaluation of LLIN usage in some selected African countries [40].

It is quite encouraging that the percentage of IPTp use reported in Yewa North LGA presented in Table 4 is close to the past 2010 RBM target of ensuring that $80 \%$ of pregnant women have access to IPTp drugs. Interestingly, some of these pregnant women received up to5 doses of IPTp which is more than the lower limit of 2 doses recommended to be given during pregnancy by WHO and the Federal Ministry of Health. This is of serious concern in view of the controversy over the safety and toxicity of giving more than 4 doses of IPTp with sulphadoxine-pyrimethamine in pregnancy which is argued could result in an increased risk of adverse drug reactions, given that 2 to 4 treatment doses of sulphadoxine-pyrimethamine is well tolerated [18]. The health care workers thus need be trained and retrained to adhere to the recommended dose of sulphadoxine-pyrimethamine in order to avoid endangering the health of patients.

Nonetheless, only a few of the pregnant women studied had received at least two doses of IPTp targeted for this at-risk population as displayed in Table 5. This finding is far below the past RBM 2005 and 2010 targets of ensuring $60 \%$ and $80 \%$ of pregnant women respectively have access to IPTp [42]. However, in view of the finding that the number of IPTp doses taken was significantly determined by how long the pregnant women had been visiting antenatal care clinics, pregnant women in the study communities thus need to be encouraged to register early for antenatal care at the nearest antenatal clinic where IPTp services are available in order to get the recommended number of doses of sulphadoxine-pyrimethamine to protect them and their unborn babies from malaria and its complications given that past studies reported malaria parasite prevalence of between $60-72 \%$ among pregnant women the south western region of the country where the study was conducted $[47,48]$. Social mobilization of men to be involved in the decision making is suggested to achieve this change.

The percentage of general IPTp use by pregnant women reported in the study is higher than the find- ings of study in a rural local government area in Southwest Nigeria [31]. It is almost similar to the IPTp uptake achieved in Malawi, higher than that of The Gambia but lower when compared with what was reported in Zambia [40]. Similarly, the result is lower than the findings in Ghana [46] and Tanzania [49].Nevertheless, the percentage that had received at least two treatment doses of IPTp in the study is below the findings reported among pregnant women in rural Kenyan communities [50] and Buea, Cameroon [51].

It is worthy of note that the results showed that the respondents' level of education and community of residence significantly influenced their awareness and use of both LLIN and IPTp. Health education programmes should therefore build on this positive link particularly targeting those with little or no education and in communities where low awareness and use of the malaria control interventions were reported.

It needs be emphasized that the low combined use of LLINs and IPTp by the pregnant women for effective protection from malaria as evident in the study is worrisome. Efforts therefore should be intensified to develop strategies of increasing awareness, demand and use of the two reinforcing health commodities by pregnant women attending antenatal clinics.

Results presented in f show the gross inadequacy of stocks of LLINs and IPTp drugs (sulphadoxine-pyrimethamine) supplied for distribution in the communities by government compared to the large number of expected target populations shown in Table 7 . To rapidly expand access to these products, it is required that government through the RBM programme managers supply them in adequate numbers that would be sufficient to meet the needs of the expected target populations.

It is disappointing that none of the health facilities visited during the survey had a copy of the National Guidelines and Strategies for malaria prevention and control during pregnancy document as at the time of the study despite the fact that this document was printed and distributed to all States for onward distribution to all LGAs and health facilities across the country. This protocol outlines basic information to guide the health care providers on steps to take and drugs to use for effective prevention of malaria in pregnancy and management and follow-up malaria cases for the implementation of IPTp that was updated by the Federal Ministry of Health in 2005 and 2010. The need to disseminate copies of the policy documents to health facilities for health workers' use particularly in the study communities is germane in impacting on the practices of health care providers in order to improve and harmonise their practices at the health facility level in the communities with those in other parts of the country for the prevention of the incidence of malaria-related complications in pregnancy. 
The low use of the LLIN and IPTp drugs could perhaps be attributed to the unavailability of the commodities at many of the health facilities, particularly the government-owned ones, where the commodities are expected to be distributed free to the target populations as evident in Table 6. The unavailability of the commodity corroborates the assertion that few public health structures reach out efficiently enough to provide good coverage of effective and affordable health commodities to rural communities [52]. It is quite unfortunate that despite the long period of malaria control programme implementation in the State, most of the respondents reported facing the constraint of inaccessibility to LLINs particularly at the health facilities where they ideally ought to be distributed free to target population, and in terms of cost and where to get the treated materials in the retail market.

The community-based delivery strategy using trained traditional birth attendants and community-directed drug distributors (CDDs) to complement access during antenatal care visits to health care facilities where routine IPTP is provided could be adopted to enhance access to sulphadoxine-pyrimethamine for IPTp. The strategy was shown to be an effective and feasible option to deliver sulphadoxine-pyrimethamine for IPTp using existing community structures and volunteers. It increased access and adherence to IPTp with low incremental cost effectiveness in the study in rural communities of Uganda [53-56]. This could be useful particularly in reaching those pregnant women who patronise traditional birth attendants and not the hospitals for antenatal care such as in the communities of Ogun State where about $10 \%$ of pregnant women receive antenatal care outside the health facilities [6].

Moreover, the low use of LLINs reported in the study is perhaps also not unconnected to the inability of the respondents to pay for the commodities obtainable in the market given the cost of the products at US\$7.00 [57] which is comparable to the retail market price of $\mathrm{N} 2,500.00$ (US\$6.94) in the study communities (Adeneye pers. comm.). The inability of the respondents to pay for the commodities in the absence of the free supplies from government can be explained in view a situation where $62.5 \%$ of population in Ogun State live on less than US\$1.00 ( $\$ 360.00)$ a day based on purchasing power parity with an average household size of five [6] vis-a-vis the overwhelming health expenditure with most of it coming from out-of-pocket expenditures, the capita household expenditure and expenditure share of household [58].

To a large extent, the absence of any information, education and communication/behaviour change and communication (IEC/BCC) materials relating to malaria control interventions being displayed at any of the health facilities and in and around the study communities visited could perhaps have contributed to the low awareness of the malaria control interventions by respondents in the study communities. It is important to state that information and education are keys for successful prevention efforts of the malaria control programme. Education campaigns are crucial, focusing on how to make proper and consistent use of LLINs, how to promptly recognize the illness in a child and know what actions to take, how to protect pregnant women and unborn children and the benefits of these. Information, education and communication/behaviour change and communication (IEC/BCC) needs to aim at increasing awareness of, and demand for, malaria products and services. It needs to target the promotion of appropriate use of these products and services for effective malaria prevention. The people need to know that diseases such as malaria are serious and can be effectively prevented and treated [59]. Adequate IEC/BCC materials such as posters, handbills and leaflets thus need be made available at the health facilities and in the communities. Given that evidence has shown that clear messages using visuals for example are likely to enhance comprehension, recall and adherence to medical instructions, $[60,61]$ the messages are suggested to be developed with visuals and made simple, unambiguous and presented in ways the people can relate to and understand; highlighting the individual benefits of LLIN and IPTp. This is essential because according to the World Health Organisation, health education structured around biomedical explanations of disease are often challenging for people to understand [62].

Limitations of this study need be pointed out at this juncture. Non-response bias was a primary limitation, some of which may be attributed to the population's poor health education and low awareness of health issues. The second limitation of the study is the focus on two LGAs of Ogun State in one part of the country. A larger study with adequate sample size that will be more representative of the geo-political zones of the country is needed to provide better and more generalisable findings for the entire country. Nonetheless, these limitations do not undermine the validity of findings of this study. The results of the study may be useful as a baseline for the malaria control improvement efforts on ACT provision for effective malaria treatment with the aim of meeting the 2030 Sustainable Development Goal for malaria [63] in Ogun State in particular and in the country in general.

\section{Conclusions}

Based on the results, use of LLIN and IPTp by pregnant women and LLIN by pregnant women and children under five is low with the current efforts to scale-up LLIN and IPTp implementation. The gap between awareness and use remains high. The LLIN and IPTp strategies of malaria control as currently implemented in the study LGAs falls short of the coverage targets. The study highlighted issues that need to be addressed for more effective 
and successful outcome in the implementation of malaria control programme in the LGAs. Efforts also need be intensified to make the LLINs and IPTp drugs more available and accessible, and where the LLINs could not be supplied in sufficient quantities to the health facilities for free access by the target populations, it should be made affordable in the marketing outlets abound in communities of the LGAs. Health promotion to explain and justify the benefits of LLINs and IPTp and to allay the fears that LLINs causes heat also need be intensified in the communities. These are important if appreciable success of the Sustainable Development Goals (SDGs) set for 2030 [63] are to be realized in reducing maternal and infant/child mortality and morbidity from malaria in the study communities, the State, and the country in general.

\section{Acknowledgements}

We sincerely acknowledge and thank the Research Assistants, the health workers of health facilities visited during the study and people of the communities where the study was carried out for all their support and cooperation. In addition, we wish to express our profound gratitude to the entire staff of the Roll Back Malaria Unit, Ogun State Primary Health Development Board, Ministry of Health, Abeokuta for their cooperation.

\section{Conflicts of Interests}

The authors declare that they have no competing interests.

\section{References}

1. Federal Ministry of Health (2010) Federal Republic of Nigeria: national policy on malaria diagnosis and treatment. Abuja: Federal Ministry of Health, National Malaria and Vector Control Division.

2. Steketee RW, Nahlen BL, Parise ME, Menendez C (2001) The burden of malaria in pregnancy in malaria-endemic areas. Am J Trop Med Hyg 64: 28-35.

3. Rogerson SJ, Mwapasa V, Meshnick SR (2007) Malaria in pregnancy: Linking immunity and pathogenesis to prevention. Am J Trop Med Hyg 77: 14-22.

4. World Health Organisation (2000) $\$ 1$ to roll back malaria Partnership 1: 9.

5. Federal Ministry of Health (2008) National Malaria and Vector Control Division. Federal Republic of Nigeria: Training manual for management of malaria in Nigeria. Abuja: Federal Ministry of Health: 6.

6. National Population Commission (NPC) [Nigeria] and MEASURE DHS ICF Marco (2009) Nigeria demographic and health survey 2008. Calverton, Maryland. National Population Commission and MEASURE DHS ICF Macro.

7. Brewster DR, Kwiatkowski D, White NJ (1990) Neurological sequelae of cerebral malaria in children. Lancet 336 : 1039-1043.

8. Marsh K (1992) Malaria - a neglected disease? Parasitology 104: S53-S69.

9. Warrell DA (1992) Cerebral malaria. Schweiz Med Wochenschr 122: 879-886.
10. Slutsker L, Taylor TE, Wirima JJ, Steketee RW (1994) In-hospital morbidity and mortality due to malaria-associated severe anaemia in two areas of Malawi with different patterns of malaria infection. Trans $\mathrm{R}$ Soc Trop Med Hyg 88: $548-551$

11. Center for International Health Information (1996) Nigeria: country health profile 1996. Arlington: Center for International Health Information. CIHI Country Health Profile Series, 10.

12. Holding PA, Stevenson J, Peshu N, Marsh K (1999) Cognitive sequelae of severe malaria with impaired consciousness. Trans R Soc Trop Med Hyg 93: 529-534.

13. Soumare M, Seydi M, Diop SA, Diop BM, Sow PS (2008) Cerebral malaria in adults at the Infectious diseases clinic in the Fann Hospital in Dakar, Senegal. Bull Soc Pathol Exot 101: 20-21.

14. National Population Commission (NPC) [Nigeria] and ICF (2019) Nigeria demographic and health survey 2018. Abuja, Nigeria, and Rockville, Maryland, USA: NPC and ICF.

15. Lengeler $C$ (2004) Insecticide-treated bed nets and curtains for preventing malaria. Cochrane Database Syst Rev 2: CD000363.

16. World Health Organisation (2004) A strategic framework for malaria prevention and control during pregnancy in the African region. WHO Regional Office for Africa, Brazzaville.

17. Hill J, Kazembe P (2006) Reaching for Abuja target for intermittent preventive treatment of malaria in pregnancy in African women: A review of progress and operational challenges. Trop Med Int Health 11: 409-418.

18. Peters PJ, Thigpen MC, Parise ME, Newman RD (2007) Safety and toxicity of sulphadoxine/pyrimethamine: Implications for malaria prevention in pregnancy using intermittent preventive treatment. Drug Saf 30: 481-501.

19. Guyatt HL, Snow RW (2004) Impact of malaria during pregnancy on low birth weight in sub-Saharan Africa. Clin Microbiol Rev 17: 760-769.

20. Challis K, Osman NB, Cotiro M, Nordahi G, Ogedge M, et al. (2004) Impact of a double dose of sulphadoxine-pyrimethamine to reduce prevalence of pregnancy in Southern Mozambique. Trop Med Int Health 9: 1066-1073.

21. Van Eijk AM, Ayisi JG, ter Kuile FO, Otieno JA, Misore AO, et al. (2004) Effectiveness of intermittent preventive treatment with sulphadoxine-pyrimethamine for control of malaria in pregnancy in western Kenya: A hospital-based study. Trop Med Int Health 9: 351-360.

22. UNICEF and Federal Ministry of Health [Nigeria] (2002) Treated bednets in Nigeria: analysis of the market for bednets, insecticides and ITNs in Nigeria. Abuja: UNICEF/ Federal Ministry of Health [Nigeria].

23. World Health Organisation (2011) World malaria report 2011. Geneva.

24. National Malaria Control Programme (2005) Malaria control in Nigeria 2005 annual report. Abuja: National Malaria Control Programme, Federal Ministry of Health.

25. Federal Ministry of Health (2005) National guidelines and strategies for malaria prevention and control during pregnancy. Abuja: Federal Ministry of Health.

26. Worrall E, Hill J, Webster J, Mortimer J (2005) Experience of targeting subsidies on insecticide-treated nets: What do we know and what are the knowledge gaps? Trop Med Int Health 10: 19-31. 
27. Hamel MJ, Odhacha A, Roberts JM, Deming MS (2001) Malaria control in Bungoma district, Kenya: A survey of home treatment of children with fever, bednet use and attendance at antenatal clinics. Bull World Health Organ 79: 1014-1023.

28. Salako LA, Brieger WR, Afolabi BM, Umeh RE, Agomo PU, et al. (2001) Treatment of childhood fevers and other illnesses in three rural Nigerian communities. J Trop Pediatr 47: $230-238$.

29. Brieger WR, Salako LA, Umeh RE, Agomo PU, Afolabi BM, et al. (2002) Promoting prepackaged drugs for prompt and appropriate treatment of febrile illnesses in rural Nigerian communities. Int Q Community Health Educ 21: 19-40.

30. Ouma PO, van Eijk AM, Hamel MJ, Sikuku E, Odhiambo F, et al. (2007) The effect of health care worker training on the use of intermittent preventive treatment for malaria in pregnancy in rural western Kenya. Trop Med Int Health 12: 953-961.

31. Akinleye SO, Falade CO, Ajayi IO (2009) Knowledge and utilization of intermittent preventive treatment for malaria among pregnant women attending antenatal clinics in primary health care centres in rural southwest Nigeria: A cross-sectional study. BMC Pregnancy Childbirth 9: 28.

32. Ekanem OJ (1996) Antimalaria activities in Nigeria: Historical perspectives. Malaria Society of Nigeria Newsletter 1 : 2-6.

33. Omikunle T (1999) Ogun State annual and investment digest. Visionlink Nigeria Ltd, Lagos.

34. Ayanlade A, Adeoye NO, Babatimehin O (2010) Climate change/variability and malaria transmission in sub-Saharan Africa: A case of Nigeria. Climate change and security: An international conference on the occasion of the $250^{\text {th }}$ anniversary of the Royal Norwegian Society of Sciences and letters, Trendheim, Norway, 2010.

35. Information, Youth, Sports and Culture Division, INLG (1997) ljebu North local government: Past and present. ljebu Ode: Take Bola Enterprises.

36. Yewa North Local Government (2003) Wind of change in Yewa north local government, Ogun State. Ayetoro: Information Department, Yewa North Local Government, 7-9.

37. Varkevisser CM, Pathmanathan I, Brownlee A (2003) Designing and conducting health system research projects, Volume 1: Proposal development and fieldwork. KIT Publishers, Amsterdam, International Development Research Centre, Brazaville, Africa Regional Office of the World Health Organisation.

38. Edelu BO, Ikemefuna AN, Emodi JI, Adimora GN (2010) Awareness and use of insecticide-treated bed nets among children attending outpatient clinic at UNTH, Enugu - the need for an effective mobilisation process. Afr Health Sci 10: $117-119$.

39. Njoroge FK, Kimani VN, Ongore D, Akwale WS (2009) Use of insecticide treated bed nets among pregnant women in Kilifi District, Kenya. East Afr Med J 86: 314-322.

40. African Union (2008) Draft progress report on the implementation of the commitments of the May 2006 Abuja special summit on HIVIAIDs, Tuberculosis and Malaria (ATM): Status report on malaria. Special Session of the African Union Conference of Ministers of Health (CAMH), Geneva.

41. National Malaria Control Programme (Nigeria) (2008) 20092010 National malaria control programme/roll back malaria business plan. Abuja: Federal Ministry of Health.
42. Roll Back Malaria (2008) Nigeria: progress and challenges towards scaling up for impact (SUFI).

43. Joshi AB, Banjara MR (2008) Malaria related knowledge, practices and behaviour of people in Nepal. J Vector Borne Dis 45: 44-50.

44. Idowu OA, Mafiana CF, Luwoye IJ, Adebanloye O (2008) Perceptions and home management practices of malaria in some rural communities in Abeokuta, Nigeria. Travel Med Infect Dis 6: 210-214.

45. Idowu OA, Mafiana CF, Sotiloye D (2008) Traditional birth home attendance and its implications for malaria control during pregnancy in Nigeria. Trans R Soc Trop Med Hyg 102: 679-684.

46. Roll Back Malaria (2008) Ghana: progress and challenges towards scaling up for impact (SUFI).

47. Okwa OO (2003) The status of malaria among pregnant women: A study in Lagos, Nigeria. Afr J Reprod Health 7: 77-83.

48. Adefioye OA, Adeyeba OA, Hassan WO, Oyeniran OA (2007) Prevalence of malaria parasite infection among pregnant women in Osogbo, Southwest Nigeria. American Eurasian Journal of Scientific Research 2: 43-45.

49. Anders K, Marchant T, Chambo P, Mapunda P, Reyburn H (2008) Timing of intermittent preventive treatment for malaria during pregnancy and the implications of current policy on early uptake in north-east Tanzania. Malar J 7: 79.

50. Gidanki PW, Noor AM, Gitonga CW, Ajanga AA, Snow RW (2008) Access and barriers to measures targeted to prevent malaria in pregnancy in rural Kenya. Trop Med Int Health 13: 208-217.

51. Takem EN, Achidi EA, Ndumbe PM (2009) Use of intermittent preventive treatment for malaria by pregnant women in Buea, Cameroon. Acta Trop 112: 54-58.

52. Nosten F, White NJ (2007) Artemisinin-based combination treatment of falciparum malaria. Am J Trop Med Hyg 77: 181-192.

53. Mbonye AK, Bygbjerg IB, Magnussen P (2007) Intermittent preventive treatment of malaria in pregnancy: The effect of new delivery approaches on access and compliance rates in Uganda. Trop Med Int Health 12: 519-531.

54. Mbonye AK, Hansen KS, Bygbjerg IC, Magnussen P (2008) Intermittent preventive treatment of malaria in pregnancy: The incremental cost effectiveness of a new delivery system in Uganda. Trans R Soc Trop Med Hyg 102: 685-693.

55. Mbonye AK, Bygbjerg IC, Magnussen P (2008) Intermittent preventive treatment of malaria in pregnancy: A new delivery system and its effect on maternal health and pregnancy outcomes in Uganda. Bull World Health Organ 86: 93-100.

56. Ndyomugyenyi R, Tukesiga E, Katamanywa J (2009) Intermittent preventive treatment of malaria in pregnancy (IPTp): Participation of community-directed distributors of ivermectin for onchocerciasis improves IPTp access in Ugandan rural communities. Trans R Soc Trop Med Hyg 103: 1221-1228.

57. Teklehaimanot A, McCord GC, Sachs JD (2007) Scaling up malaria control in Africa: An economic and epidemiological assessment. Am J Trop Med Hyg 77: 138-144.

58. National Bureau of Statistics (2012) Nigeria poverty profile 2010. Abuja: National Bureau of Statistics.

59. (1998) Advocacy to address disabling diseases: TDR holds brainstorming session. TDR News 56 .

60. Houts PS, Doak CC, Doak LG, Loscalzo MJ (2006) The role of pictures in improving health communication: $A$ re- 
view of research on attention, comprehension, recall and adherence. Patient Educ Couns 61: 173-190.

61. Katz MG, Kripalani S, Weiss BD (2006) Use of pictorial aids in medication instructions: A review of the literature. Am J Health Syst Pharm 63: 2391-2397.

62. World Health Organization (1995) Towards the healthy women counselling guide. Geneva: World Health Organisation. TDR/GEN/95.1.

63. Lee H, Pollitzer E (2015) The Role of Gender-based Innovations for the UN Sustainable Development Goals Toward 2030: Better Science and Technology for All. (Edition 1). Seoul: Korea Center for Women in Science, Engineering and Technology (WISET). 